\title{
Beyond Planning Tools: Experiential Learning in Climate Adaptation Planning and Practices
}

\author{
Kristen M. Schmitt ${ }^{1,2, *(\mathbb{D}}$, Todd A. Ontl ${ }^{1,2}{ }^{\mathbb{D}}$, Stephen D. Handler ${ }^{2,3}$, Maria K. Janowiak ${ }^{2,3}$, Leslie A. Brandt ${ }^{2,3}$, \\ Patricia R. Butler-Leopold 1,2, P. Danielle Shannon 1,2, Courtney L. Peterson 2,4 (D) \\ and Christopher W. Swanston 2,3 (D)
}

1 College of Forest Resources and Environmental Science, Michigan Technological University, Houghton, MI 49931, USA; taontl@mtu.edu (T.A.O.); pleopold@mtu.edu (P.R.B.-L.); dshannon@mtu.edu (P.D.S.)

2 Northern Institute of Applied Climate Science, and USDA Northern Forests Climate Hub, Houghton, MI 49931, USA; stephen.handler@usda.gov (S.D.H.); maria.janowiak@usda.gov (M.K.J.); leslie.brandt@usda.gov (L.A.B.); courtney.peterson@colostate.edu (C.L.P.); christopher.swanston@usda.gov (C.W.S.)

3 Northern Research Station, USDA Forest Service, Houghton, MI 49931, USA

4 Forest and Rangeland Stewardship Department, Colorado State University, Fort Collins, CO 80523, USA

* Correspondence: kmschmit@mtu.edu; Tel.: +1-218-626-4334

Citation: Schmitt, K.M.; Ontl, T.A.; Handler, S.D.; Janowiak, M.K.; Brandt, L.A.; Butler-Leopold, P.R.; Shannon, P.D.; Peterson, C.L.; Swanston, C.W. Beyond Planning Tools: Experiential Learning in Climate Adaptation Planning and Practices. Climate 2021, 9, 76. https://doi.org/10.3390/cli9050076

Received: 12 April 2021

Accepted: 29 April 2021

Published: 7 May 2021

Publisher's Note: MDPI stays neutral with regard to jurisdictional claims in published maps and institutional affiliations.

\begin{abstract}
In the past decade, several dedicated tools have been developed to help natural resources professionals integrate climate science into their planning and implementation; however, it is unclear how often these tools lead to on-the-ground climate adaptation. Here, we describe a training approach that we developed to help managers effectively plan to execute intentional, climate-informed actions. This training approach was developed through the Climate Change Response Framework (CCRF) and uses active and focused work time and peer-to-peer interaction to overcome observed barriers to using adaptation planning tools. We evaluate the effectiveness of this approach by examining participant evaluations and outlining the progress of natural resources projects that have participated in our trainings. We outline a case study that describes how this training approach can lead to place and context-based climate-informed action. Finally, we describe best practices based on our experience for engaging natural resources professionals and helping them increase their comfort with climate-informed planning.
\end{abstract}

Keywords: climate change; adaptation planning; natural resources; training; climate framework; climate-informed management

\section{Introduction}

There is often a mismatch between broad-scale climate impacts information and finer scale management decisions in natural resources management [1-4]. From 2010-2020, several publications, handbooks, guides, and frameworks were designed to bridge this gap and help professionals integrate climate science into their planning processes [5-13]. These resources help managers develop, evaluate, and implement climate change adaptation strategies, rather than solely providing information on climate impacts and vulnerabilities. However, it is unclear how often and effectively these tools are being used to plan and execute intentional, transparent adaptation actions [14-17]. There are still relatively few examples of portfolios of dedicated natural resources-focused adaptation projects [16,18]. Training in climate adaptation tools often involves a substantial time commitment by professionals, requiring time away from existing obligations and creating a perceived increase in their workload. This opportunity cost can seem especially high when workshops are conducted with passive methods or theoretical exercises that can be difficult to connect to real-world situations. 
Beginning in 2013, the Northern Institute of Applied Climate Science (NIACS) has developed and refined a training approach on climate adaptation in natural resources management, applied through the Climate Change Response Framework (CCRF). Each training event was designed to provide practical, applied outcomes to a specific audience and not as a research-driven experiment. Our years of training experience coupled with feedback from participants may provide insight for professionals working in climate adaptation who are interested in accelerating the adoption of climate adaptation tools and frameworks. We maintain that the most effective trainings for natural resources professionals shift the focus from passive learning about a tool or process to active and focused work time that allow participants to pursue their own work while using a tool [19].

We provide an in-depth description of a training approach that has been developed and applied through the CCRF, led by NIACS, to reduce opportunity costs and increase direct application to planning needs [10]. This description does not include a complete review of climate adaptation training methods, but rather offers insight on our approach to closing the noted gap between climate adaptation tools and intentional, applied climate adaptation actions.

We derive and discuss lessons learned from participant evaluations and successful implementation of natural resources projects after using this approach. Finally, we describe best practices for this training approach in particular, and providing a structured process that can accommodate flexible management contexts in general, with the broad aim of advancing climate services.

\section{Overview of Tools and Approach}

We launched the CCRF in 2009 to identify and develop practical approaches to integrating climate change considerations into ecosystem management in the United States (U.S.), with particular emphasis on the upper Midwest and Northeast [20]. Reliance on co-production between natural resources scientists and professionals is a core principle of the CCRF, grounded in both inclusion and pragmatism [10]. This essential principle is shared by other climate services providers $[2,4,17,21]$. The CCRF has grown to include a diverse portfolio of tools, products, and approaches that were co-created by natural resources scientists and professionals. The original CCRF portfolio was released through the Forest Adaptation Resources general technical report $[7,10]$ and has since expanded through wider scientific publication and internet delivery [22]. Dozens of organizations have collaborated through the CCRF to develop several ecoregional vulnerability assessments for forest ecosystems $[23,24]$ but the most dynamic ongoing work has involved hundreds of organizations that have generated adaptation demonstration projects using CCRF tools and approaches. Foremost among these tools are the Adaptation Workbook and the adaptation "menus" of strategies and approaches [10,25], which are designed to be used together in project planning (Figure 1). 


\section{ADAPTATION STRATEGIES AND APPROACHES}

Provides topical menus of broad adaptation strategies, more specific approaches, and example tactics.

\section{ADAPTATION WORKBOOK}

Outlines a series of steps for incorporating climate change into existing management

\section{1}

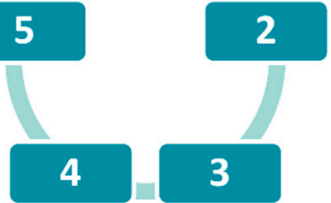

\section{ADAPTATION DEMONSTRATIONS}

Provides real-world examples of how the above can be used together to plan intentional, transparent adaptation actions.

Figure 1. Adaptation tools within the CCRF. Figure reproduced with permission [10].

\subsection{Adaptation Workbook}

The Adaptation Workbook $[10,25]$ is a simplified adaptive management process optimized for climate adaptation and delivered as a step-by-step workbook. It was designed as a decision support tool to generate focused, explicit climate considerations and proposed actions for integration into broader planning and decision making. It is "simplified" in the sense that there are more comprehensive decision support processes focused on climate adaptation planning $[5,11]$. The published Adaptation Workbook is what survived testing and feedback by natural resources professionals using this process with their own real-world projects; it includes what they identified as useful and necessary. Nonetheless, it is not a simple process and largely presumes professional experience and judgement. Following the stepwise workbook generates an in-depth examination of a project and requires considerable knowledge and information about the project area, potential management practices, and organizational capacity. Coaching users on the Adaptation Workbook in a workshop setting has helped first-time users feel comfortable with climate change impacts and adaptation topics, and in using the process in subsequent project planning and application.

\subsection{Adaptation Strategies Menus}

The adaptation strategies menus do not provide recommendations, but are instead resources for brainstorming relevant adaptation actions, and are used in the Adaptation Workbook to link specific on-the-ground management actions with broader adaptation intent. The initial menus focused on forestry issues in rural and urban settings $[7,10,20]$, but continued evolution of the CCRF has led to the creation and publication of additional adaptation menus that include a wider variety of ecosystems and management topics. Published menus exist for agriculture [26], forested watersheds [27], tribal and indigenous perspectives [28], forest carbon stewardship [29], outdoor recreation [30], inland lakes [31], open wetlands [32] and California forests [33]. Additional menus are in preparation and review for other interest areas, including wildlife management, coastal ecosystems, 
grasslands, and fire-dependent ecosystems. Menu development varies based on topic and specific authors, but the collation and tiered organization of strategies and approaches is typically informed by review of scientific literature and best management practices, interviews with researchers and professionals, outreach at professional and scientific meetings, iterative rounds of testing and review with managers and formal peer review prior to publication e.g., $[27,30]$.

\subsection{Applied Planning and Practices Workshops}

From 2013 to February 2020, the Northern Institute of Applied Climate Science (NIACS) and multiple partner organizations conducted 42 in-person Adaptation Planning and Practices workshops (APPs) and eight online APPs using the Adaptation Workbook and strategies menus (Supplementary Material S1). Several factors distinguish an APP from the many other types of consultations, trainings, classes, sessions and webinars that are also a part of regular work as a climate services organization. Fundamentally, an APP is an experiential training in which participants bring their own natural resources management projects with the expectation that they will use the workshop to generate intentional, documented, and actionable adaptation tactics for their project. The workshop provides dedicated work time for participants to complete the Adaptation Workbook steps with ample coaching and activities, and minimal presentations. Multiple teams often representing diverse organizations work on different projects in parallel, engaging in periodic peer-to-peer learning and brainstorming while sharing project information and proposed tactics. Outcomes include custom climate adaptation plans that can move from planning to implementation and evaluation over time [22].

\section{APP Process}

We first developed the APP process in 2013 as participants in our general climate adaptation trainings increasingly indicated that they wanted less conceptual discussion of the Adaptation Workbook and more actual work with the tool. Yet on their own, many felt stymied by the learning curve and were challenged in setting aside the necessary time to use the Adaptation Workbook in the press of their day-to-day activities. Our response was to design a workshop process that emphasized hands-on work time and coaching. Over the course of the 50 training events held from 2013 to 2020, we rapidly evolved the structure of this "working workshop" based on early feedback and we continue to adjust it to meet participant needs. Here, we include descriptions of the common elements of an APP.

\subsection{APP Duration, Size, and Participation}

APPs are designed for professionals who want to get their work done while engaging in hands-on learning. This creates a functional upper limit on the size of the workshop and a lower limit on the duration. We typically run each APP with 1-2 instructors who set the agenda and facilitate the meeting. APPs generally take place over 1.5-2 days and require some pre- and post-workshop activity, providing the opportunity to complete the Adaptation Workbook. This time requirement has shown to be manageable for many professionals. Participants are limited to approximately $30-35$ people (7-10 project teams) to encourage active engagement and allow for adequate interaction among project teams. We encourage participants to form teams with members from different professional disciplines (e.g., biologist, silviculturist, hydrologist, etc.), which brings a wider range of perspectives to risk identification and problem solving. Exact participant disciplines vary, but all APPs are targeted towards professionals engaged in planning and decision making for natural resources management. An individual APP is often centered around a particular area or theme, leading us to recruit workshop participants from a particular geography or ecoregion (e.g., New England and New York forests, urban forests in the Twin Cities), organization or stakeholder group (e.g., Minnesota Department of Natural Resources, Great Lakes Tribes and tribal partners) or resource area (e.g., forested watersheds, wildlife refuges) 
to further promote engagement. These groupings can create a combination of shared perspectives and diverse project goals that help the participants bridge organizational divides, learn from each other and recognize common values.

\subsection{Pre-Work}

APPs involve pre-assigned work to capitalize on limited in-person time. Assignments often include reading on regionally relevant climate change vulnerabilities e.g., [23,34-36] and participation in a webinar introducing key climate impacts and adaptation concepts. Each project team is required to submit a project proposal prior to the workshop. APP instructors discuss project ideas with teams to ensure they are a good fit for the available time. An appropriate project for an APP would be a real-world project that generates discussion and introduces participants to the adaptation planning process, but that is not too complex to significantly slow progress during the workshop itself. Instructors can also help project teams delineate specific project goals and objectives. Ideally, this pre-work helps participants arrive at the workshop with an understanding of regional or sector-relevant climate change impacts, and a management project with clearly articulated goals and objectives at an appropriate scale.

\subsection{Subject Matter Experts and Presentations}

Presentations are typically minimized in APPs but are included when requested by co-hosts and participants. There is a limited amount of information that professionals have time to assimilate before the workshop, even with pre-assigned work. Special presentations are most often given by invited experts who provide targeted detail on regional climate change impacts to resources of interest. Such talks may cover the relationship between climate trends and local forests, regional wildfire or wildlife vulnerabilities, for example. Expert presentations are typically given by university researchers, agency scientists or staff, and experienced professionals. These trusted messengers and recognized local experts add credibility to the information and ensure its relevance.

\subsection{Adaptation Workbook and Activities}

The core of each APP is the time dedicated for participants to work through the Adaptation Workbook [10] using their own projects, while providing opportunities for semi-structured and structured discussions within and among project teams. Instructors often present real-world examples that convey the considerations and actions taken by other teams who have completed the Adaptation Workbook. During an APP, completing each of the five main Adaptation Workbook steps generally involves: (1) a short presentation (5-20 $\mathrm{min}$ ) on the step, often including an example from a previous project; (2) guiding questions to consider with instructions on filling out the worksheet(s); (3) small-group discussion as project teams work on completing their worksheets; and (4) a large-group activity to share information between project teams (Table 1 and Supplementary Material S2).

\section{Workshop Activities}

We use group activities in each APP to promote discussion in and among project teams, to reinforce crucial adaptation concepts, and to spark creative thinking. Group activities with the entire APP cohort are essential to facilitating peer-to-peer learning and helping participants consider how the Adaption Workbook process can be applied to different settings, goals, and objectives. These also add variety to the workshop format and introduce physical and mental breaks. 
Table 1. Key concepts for leading project teams through the steps of the Adaptation Workbook during an APP. See S2 for more information on process and group activities.

\begin{tabular}{|c|c|c|}
\hline Workbook Step & Purpose & Guiding Questions \\
\hline 1 & $\begin{array}{l}\text { Describe project location and } \\
\text { define management goals and } \\
\text { objectives }\end{array}$ & $\begin{array}{l}\text { 1.1 Where are you working? } \\
\text { 1.2 What are your management goals and } \\
\text { plans for this area? }\end{array}$ \\
\hline 2 & $\begin{array}{l}\text { Assess site-specific climate } \\
\text { change impacts and } \\
\text { vulnerabilities }\end{array}$ & $\begin{array}{l}\text { 2.1 How might the area be uniquely } \\
\text { affected by climatic change and } \\
\text { subsequent impacts? } \\
\text { 2.2 How might regional impacts be } \\
\text { different in the project area? }\end{array}$ \\
\hline 3 & $\begin{array}{l}\text { Evaluate management } \\
\text { objectives given projected } \\
\text { impacts and vulnerabilities. }\end{array}$ & $\begin{array}{l}\text { 3.1 What climate-related management } \\
\text { challenges or opportunities might occur? } \\
\text { 3.2 Can current management meet } \\
\text { management goals? } \\
\text { 3.3 Do goals need to change? }\end{array}$ \\
\hline 4 & $\begin{array}{l}\text { Identify adaptation } \\
\text { approaches and tactics for } \\
\text { implementation }\end{array}$ & $\begin{array}{l}\text { 4.1 What actions can enhance the ability } \\
\text { of the ecosystem to adapt to anticipated } \\
\text { changes and meet management goals? } \\
4.2 \text { How will future managers know } \\
\text { what you were trying to do? }\end{array}$ \\
\hline 5 & $\begin{array}{l}\text { Monitor and evaluate the } \\
\text { effectiveness of implemented } \\
\text { actions. }\end{array}$ & $\begin{array}{l}5.1 \text { How do we know if the selected } \\
\text { actions were effective? } \\
5.2 \text { What can we learn from these actions } \\
\text { to inform future management? }\end{array}$ \\
\hline
\end{tabular}

The following example activity on feasibility ranking illustrates how group activities support broader APP outcomes. In Adaptation Workbook step 3, we ask each team to consider specific climate-related challenges and opportunities to meeting their management objectives (aspects that might make their objectives harder or easier to achieve). We may run an initial group activity to have project teams share these challenges and opportunities with one another, and to encourage participants to examine their objectives through a climate lens rather than identifying more general concerns. After teams explore this question, we often conduct an activity to help project teams to slow down and take a critical look at the feasibility of meeting their management objectives, given climate considerations. We provide project teams with three large sticky notes $\left(5.5^{\prime \prime} \times 8^{\prime \prime}\right)$ and ask them to summarize one management objective on each note in large writing. On the classroom wall or floor, we create a line using painter's tape and label it as a continuum of feasibility ranging from low to medium to high. We ask each project group to consider the feasibility of meeting their selected objectives in the short-term ( $<10$ years) given "business as usual" management, and to place each note on the continuum.

After project teams have placed their objectives, we facilitate a conversation with the full APP cohort to highlight key details and concepts. Questions that we typically discuss include: what objectives are rated as easy or hard to achieve under business as usual management and why? Are there any objectives that you think need to change? Are there any that you would consider high-risk but necessary? We then ask project teams to move their sticky notes to show where they would place their objectives if considering feasibility in the long-term ( $>30$ years). Discussion questions that follow might include: why does your objective become more difficult to achieve (or easier) in the long-term? How does climate change contribute to this? Would your objective need to change over time? Ultimately, this activity helps project teams critically examine their goals and objectives through a climate lens, consider which objectives may be low or high risk, examine how objectives might have to change over time and in response to new information and consider how to communicate this to stakeholders. 


\subsection{Variations to the APP Format}

There are numerous minor variations in the basic version of the APP agenda, but two major variants merit description. These accommodate needs of co-hosts or the changing use and capabilities of technology.

\subsubsection{The "Community Building" Model}

This variant places more emphasis and time on information delivery and community interaction, but nonetheless spends a full day in the standard APP model. Organizations who wish to co-host an APP may have stakeholders who are interested in climate change but do not manage land or do not have projects ready to bring to the workshop. We include these stakeholders with a 2-day workshop divided into two distinct parts: one full day of presentations and structured discussion on locally relevant climate and ecosystem management subjects for a broad audience, followed by a one-day focused workshop for a subset of attendees who will complete the Adaptation Workbook. The first day may be larger (60-100 participants) and the APP may be held in conjunction with a larger event or conference related to climate change and/or natural resource management. Although this allows less in-person time to complete the Adaptation Workbook, much of the background information and context on regional climate changes, vulnerabilities, and adaptation concepts can be provided on the first day of the workshop, allowing participants to move through the workbook steps more quickly on day two.

\subsubsection{Online APP Course}

Online APP courses provide training possibilities for professionals who may not have the funds or ability to travel to a two-day training. In 2016, NIACS and the USDA Northern Forests Climate Hub started hosting online APPs using the online version of the Adaptation Workbook [25]. These courses take place over seven weeks with weekly engagements lasting approximately $2 \mathrm{~h}$ each session. The online APP course follows a similar progression as an in-person APP but rolls more of the traditional pre-work materials into the seven week course. Online assignments are offered for each APP through a customizable learning management system. Adaptation Workbook step presentations, group discussions, and activities contain similar questions and learning objectives as those covered in-person, but the delivery is modified to fit a distance-learning format. The timing of this template can afford more interaction with the instructors, albeit not in person. Likewise, there is more time for reflection and analysis by participants as they move through Adaptation Workbook steps. Finally, the timing and technology can allow multiple instructors to participate remotely in instruction and coaching, expanding course capacity to as much as 60 participants and over 45 projects.

\section{APP Evaluation and Outcomes}

We designed the APP to help participants move from perceiving climate change as a subject too large and daunting to integrate into everyday planning, to understanding how to break the topic into manageable steps using the Adaptation Workbook. APPs aim to help participants leave a training feeling equipped to include climate-informed actions in subsequent projects. We assess the effectiveness of the APPs in several ways, including continued interest (requests and attendance), formal and informal participant feedback, and project implementation. The scale and timing of these metrics vary, but the constant is our commitment to responsiveness and continued improvement.

\subsection{Participant Perceptions and Learning}

One consistent source of feedback is a standard written evaluation that we collect following each APP. Evaluations were principally designed to provide instructors with feedback to improve the training process and not as research tools to comprehensively compare outcomes across workshops. These evaluations help us understand whether participants have learned key concepts, which training elements were effective, and how 
participants plan to use information going forward. The evaluation contains ranking questions using a Likert scale of $1-5$, and space for open-ended comments (Supplementary Material S3). Evaluation data are normally synthesized and shared with APP co-hosts, used to follow up on specific requests from participants, and used to continually evaluate APP effectiveness on a workshop to workshop basis. Assessment of evaluations conducted through February 2020 ( $n=467$; a response rate of $49 \%$ of workshop attendees) demonstrate participant perceptions of workshop effectiveness in achieving APP goals.

Most respondents felt the workshop approaches were effective and increased their overall knowledge and understanding of climate impacts and potential adaptation responses. In particular, responses indicated a high level of agreement that the combination of activities, group discussion, and description of real-world examples were an effective approach at helping people engage in and understand the adaptation planning process (Table 2). Responses to questions addressing participant's level of knowledge before and after the workshop indicate a consistent increase in understanding and comfort level across multiple aspects of adaptation planning (Figure 2). For example, prior to workshops the respondents reported the lowest level of agreement with the ability to identify adaptation strategies (2.6; scored on a Likert scale from $1=$ low to $5=$ high) and translating strategies into actionable tactics (2.5) across the six knowledge assessment categories. These same questions had the highest levels of improvement following the workshops, with a score increase of 1.5 within both categories. Highest levels of reported pre-workshop knowledge, along with the lowest change relative to post-workshop level of knowledge was reported for understanding local impacts of climate change (Figure 2). The lowest level of pre- and post-workshop knowledge reported by participants related to their overall comfort in their ability to help species and ecosystems adapt to climate change (Figure 2), suggesting there are additional factors limiting people's perceived ability to adapt to changes.

Table 2. Average evaluation scores $(n=467)$ addressing the effectiveness of different workshop components at the training, intent to apply elements of the training moving forward, and factors limiting adaptation planning (Score: $1=$ Not at all; 5 = Definitely).

\begin{tabular}{|c|c|c|}
\hline Category & Question & $\begin{array}{l}\text { Score } \\
\text { (Standard Error) }\end{array}$ \\
\hline \multirow{4}{*}{ At the training } & $\begin{array}{l}\text { The first activity on climate change impacts and vulnerabilities helped me get to } \\
\text { know the other projects and participants }\end{array}$ & $4.41(0.04)$ \\
\hline & $\begin{array}{l}\text { The examples presented prior to each breakout session helped me to understand } \\
\text { what I needed to accomplish in each step }\end{array}$ & $4.25(0.04)$ \\
\hline & $\begin{array}{l}\text { The whole group discussion following the individual breakouts provided } \\
\text { valuable feedback and new insights }\end{array}$ & $4.50(0.03)$ \\
\hline & $\begin{array}{l}\text { The presentation on adaptation strategies and approaches helped me to } \\
\text { understand their usefulness }\end{array}$ & $4.36(0.04)$ \\
\hline \multirow{3}{*}{ After the training } & $\begin{array}{l}\text { How likely are you to incorporate the plans you developed into in-the-ground } \\
\text { actions? }\end{array}$ & $4.11(0.04)$ \\
\hline & $\begin{array}{l}\text { How likely are you to apply the Forest Adaptation Resources workbook process } \\
\text { to another project in the next year? }\end{array}$ & $3.83(0.05)$ \\
\hline & $\begin{array}{l}\text { How likely are you to share what you learned at this training with other } \\
\text { managers in your organization? }\end{array}$ & $4.41(0.04)$ \\
\hline \multirow{6}{*}{ Limiting factors } & Resources & $3.66(0.06)$ \\
\hline & Other work responsibilities of higher priority & $3.64(0.05)$ \\
\hline & Guidance or know-how on adaptation & $2.56(0.05)$ \\
\hline & Public support & $2.63(0.05)$ \\
\hline & Support within your organization & $2.40(0.06)$ \\
\hline & Support/direction from supervisor & $2.13(0.06)$ \\
\hline
\end{tabular}




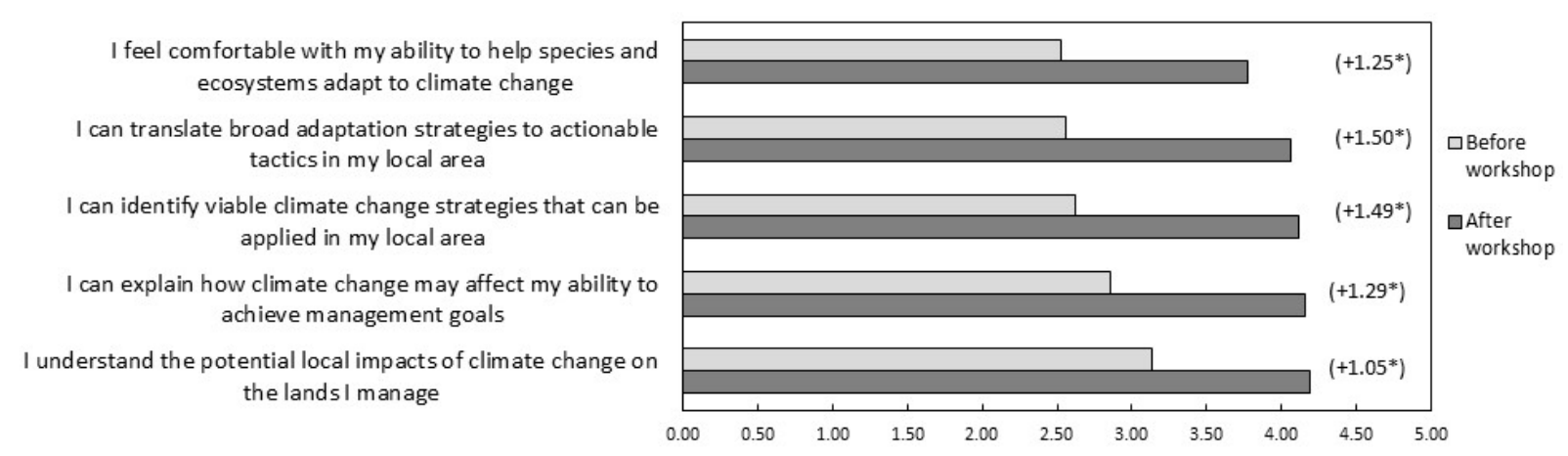

Figure 2. Summary of pre- and post-workshop assessment of participant's level of knowledge of climate impacts and adaptation summarized from 467 evaluations ( $1=$ Low level; $5=$ High level). Parentheses indicate change between before and after workshop; ${ }^{*}$ indicates $p<0.0001$ for paired t-test comparing before and after workshop.

Perhaps one of the most important indicators of a successful workshop is when participants leave with the intention to integrate the knowledge they have gained into their work. Post-APP evaluation questions reveal that attendees felt they were likely to incorporate their adaptation plans into on-the-ground actions (4.1), as well as apply the Adaptation Workbook process to another project in the next year (3.8, Table 2). In addition to an intent to implement the information learned, participants indicated a strong likelihood of sharing the information they learned at the APP training with others in their organization (4.4).

We asked participants what might limit their ability to integrate adaptation into their planning after participating in the workshop. The evaluation offered six possible limiting factors based on informal feedback from managers on common limitations, as well as the option for an open-ended response. On average, respondents indicated that a lack of guidance or know-how on adaptation was not an important limiting factor, suggesting that respondents felt APPs were effective at providing the necessary information on how to approach adaptation planning in their future work. Evaluation results also suggested that support for adaptation planning from a supervisor or the public was not a significant limiting factor. Respondents indicated they could be best aided in their future adaptation planning by having access to additional resources. For example, assessments of the adaptation needs of forest managers in New England indicated that guidance on developing site-level recommendations for adaptation would be helpful for enhancing adaptation efforts in the region [37]. Unsurprisingly, respondents also indicated one of the greatest barriers to adaptation planning was having the necessary time given other work obligations (Table 2).

\subsection{Community Sharing and Connection}

The APPs are most specifically meant to support professionals in implementing climate-informed actions in their ecosystem management work. However, they also help contribute more broadly to enhancing communication and community learning through the CCRF. The effectiveness of peer-to-peer learning and the "show me" culture of natural resources professionals have given rise to a long tradition of case studies and demonstration projects in the United States [38]. We seek to take advantage of this culture by highlighting "adaptation demonstrations," which tell the stories of organizations' places, goals, perceived climate threats and opportunities, and adaptation responses [22]. Following each APP, projects that have undergone Adaptation Workbook planning are considered adaptation demonstration projects; project teams with plans to implement their project are invited to create an adaptation demonstration webpage using the work completed at the APP. The APPs have resulted in over 450 adaptation demonstration projects, many of which have moved beyond the initial Adaptation Workbook planning (start-up) phase to be integrated into planning documents and implemented on the ground. Over 180 of these are described in webpages that highlight how the project team considered each step 
of the adaptation workbook, describe concrete examples of adaptation tactics within the context of that project, and provide information on the state of planning, implementation, or evaluation of the project [22]. These demonstration webpages offer an opportunity for natural resources managers to learn from one another and to see how climate change is being considered in on-the-ground management across land ownerships and ecosystems. They also provide organizations a chance to communicate how they are considering and adapting to climate change through the lens of their own values and goals.

APPs also allow participants the opportunity to connect with one another and with instructors on the topic of climate change adaptation. Enhancing connections between professionals who may be working in similar fields or geographical areas can be invaluable in supporting ongoing adaptation work. Rather than treating each APP as a one-time event, instructors provide post-workshop support to project teams and individuals. This can involve providing additional climate change vulnerability information, making connections between project teams and subject experts, and following up on the implementation of climate-informed actions. Instructors may collect copies or photos of completed worksheets to better understand what adaptation choices teams are making and to help follow up with project teams [16]. Providing ongoing support can be a key factor in helping groups document their actions and successes, and eventually move from planning to action.

Depending on the specific workshop activities, APPs can also give managers the chance to practice effectively communicating their planned adaptation actions to potential stakeholders, and putting these actions in the context of their adaptation intent. Misunderstood information, unintended interpretation, and other communication issues have been cited as key barriers at multiple stages of climate adaptation, making these important skills to practice [14].

\subsection{Case Study: Forest Conservation and Stewarship Summit and Adaptation Workshop}

The standard APP process (Section 3) may be best illustrated through an example of a typical training event (Supplementary Materials S4 and S5).

In the fall of 2016, we held a 2-day APP in Boyne Falls, MI, in partnership with Heart of the Lakes, an organization representing land trusts within the state of Michigan, and the Inter-Tribal Council of Michigan, representing tribal nations in Michigan. Partners co-hosting this APP anticipated broad interest in the theme of forest conservation in an era of rapid change, targeting the workshop toward natural resources professionals from Michigan's tribes, land conservancies and other organizations. We accommodated this by designing the first day as a large summit for a general audience, including a panel discussion and several expert speakers that covered topics on emerging forest threats like climate change, deer herbivory, and forest pests. The second day provided an opportunity for a smaller cohort to use the Adaptation Workbook to plan climate adaptation actions for their own real-world projects.

Approximately 80 people participated in the first day of presentations and group discussion. The second day included a subset of 18 participants representing seven different management projects, with two to four people per project team. Each project team went through a facilitated process using the Adaptation Workbook (Table 1). After the completion of the APP, the workshop instructor followed up with the project teams who indicated an intent to move toward implementation of their project, and worked with these teams to finalize their concepts. In total, five of the seven project teams pursued further action on their adaptation projects and summarized their project as an adaptation demonstration webpage [22]. These five projects are briefly outlined below (Table 3). 
Table 3. Select summarized project goals, climate risks, and adaptation actions from five demonstration projects from the Forest Conservation and Stewardship Summit and Adaptation Workshop.

\begin{tabular}{|c|c|c|c|}
\hline $\begin{array}{l}\text { Organization and } \\
\text { Demonstration Link }\end{array}$ & Project Goal(s) & Select Climate Risks & Select Adaptation Actions \\
\hline Leelenau Conservancy [39] & $\begin{array}{l}\text { Promote a diverse and productive } \\
\text { forest }\end{array}$ & $\begin{array}{l}\text { Climate-related tree stress combined } \\
\text { with damage from oak wilt and beech } \\
\text { bark disease. } \\
\text { Increased deer herbivory. }\end{array}$ & $\begin{array}{l}\text { Install deer exclosures ( } 35 \text { acres). } \\
\text { Conduct a timber harvest to salvage beech } \\
\text { and ash. } \\
\text { Plant tree species that may be favored by } \\
\text { climate change (tulip tree, shagbark hickory, } \\
\text { white oak, sassafras). }\end{array}$ \\
\hline $\begin{array}{l}\text { Bay Mills Indian } \\
\text { Community [40] }\end{array}$ & $\begin{array}{l}\text { Promote wildlife habitat. } \\
\text { Promote a diversity of forest types. }\end{array}$ & $\begin{array}{l}\text { Increasing precipitation combined } \\
\text { with emerald ash borer damage-risk } \\
\text { that lowland hardwood stands may } \\
\text { convert to non-forested open } \\
\text { wetlands. }\end{array}$ & $\begin{array}{l}\text { Plant tree species to compensate for the loss } \\
\text { of ash, including species that may do well } \\
\text { under future climates (inc. hackberry, red } \\
\text { maple, northern white cedar, river birch, } \\
\text { swamp white oak, basswood, sycamore, } \\
\text { chokecherry, and disease-resistant American } \\
\text { elm). }\end{array}$ \\
\hline $\begin{array}{l}\text { Little Traverse } \\
\text { Conservancy [41] }\end{array}$ & $\begin{array}{l}\text { Create and maintain } \\
\text { early-successional habitat for upland } \\
\text { game birds and declining species such } \\
\text { as the golden-winged warbler }\end{array}$ & $\begin{array}{l}\text { Increasing stress for boreal tree } \\
\text { species that provide important bird } \\
\text { habitat, such as quaking aspen. }\end{array}$ & $\begin{array}{l}\text { Conduct a forest harvest to regenerate } \\
\text { quaking aspen and provide a younger age } \\
\text { class. } \\
\text { Plant tree species that may be favored by } \\
\text { climate change in harvested areas (white oak, } \\
\text { burr oak). } \\
\text { Plant native grass and shrub species to } \\
\text { restore an old agricultural field. }\end{array}$ \\
\hline $\begin{array}{l}\text { Pokagon Band of Potawatomi } \\
\text { Department of Natural } \\
\text { Resources [42] }\end{array}$ & $\begin{array}{l}\text { Maintain three culturally important } \\
\text { tree species (paper birch, black ash, } \\
\text { and northern white-cedar). }\end{array}$ & $\begin{array}{l}\text { Decreasing habitat suitability for } \\
\text { culturally important tree species. }\end{array}$ & $\begin{array}{l}\text { Plant two separate groves of northern } \\
\text { white-cedar that cross a variety of soil and } \\
\text { moisture gradients. } \\
\text { Install a deer exclosure to protect newly } \\
\text { planted seedlings. } \\
\text { Consider promoting blue ash as an } \\
\text { alternative to black ash (may be less } \\
\text { susceptible to emerald ash borer). }\end{array}$ \\
\hline $\begin{array}{l}\text { Little Traverse Bay Band of } \\
\text { Odawa Indians [ } 43 \text { ] }\end{array}$ & $\begin{array}{l}\text { Maintain and improve cultural values } \\
\text { on the site (including culturally } \\
\text { important tree species). } \\
\text { Improve wildlife habitat and forest } \\
\text { health. }\end{array}$ & $\begin{array}{l}\text { Decreasing habitat suitability for } \\
\text { northern white-cedar. } \\
\text { Potential risks to forest health and } \\
\text { wildlife habitat. }\end{array}$ & $\begin{array}{l}\text { Plant cedar from a seed source in southwest } \\
\text { Michigan. } \\
\text { Restore old fields and canopy gaps by } \\
\text { planting species that may increase in } \\
\text { northern Michigan (swamp white oak, bur } \\
\text { oak, cottonwood) as well as southern seed } \\
\text { sources of native species (sugar maple, red } \\
\text { maple). }\end{array}$ \\
\hline
\end{tabular}

These five adaptation demonstrations represent some of the real complexity and variety in how project teams move through the Adaptation Workbook and from planning to implementation. Project teams may be intently focused on a well-defined management objective for their property, or they may have several broader goals they wish to pursue. The specificity of these goals can influence how they consider feasibility, as well as the formulation of their adaptation actions. Often, teams will discover additional questions they have to answer before following through on a specific action or they may opt to revise their management objectives based on the perceived feasibility of success. Likewise, implementing adaptation on the ground can be messy. Project teams may pursue their selected adaptation actions based on available time, funding, or stakeholder buy-in. Therefore, some adaptation projects are implemented on an orderly schedule while others proceed in a more piecemeal fashion.

Taken individually, these projects are useful examples of how an individual or organization can assess risk according to their own values and respond appropriately. Together they add to a growing community of practice and a diverse set of examples that can help accelerate the understanding and implementation of climate adaptation responses in natural resources.

\section{Best Practices in Balancing Structure and Flexibility in Training}

In our experience, dedicated training has been instrumental in introducing climate adaptation planning processes, such as the Adaptation Workbook and the adaptation strategies menus, to a broader audience than they would have otherwise reached. Trainings like the APPs allow the space and time for professionals to learn what climate-informed planning might look like in a variety of contexts by working on their own project, learning 
and brainstorming with their peers from different organizations and by receiving feedback on how they have approached climate challenges and opportunities in natural resources management. APPs have also helped reach managers that may not have the time or resources to tackle adaptation planning on their own, and have led to continued use of the Adaptation Workbook. Ultimately, this means that intentional, climate-informed actions are getting implemented on the landscape and ideally minimizing climate-related risks to natural resources. From our experience leading 50 in-person and online APPs, representing nearly 1200 professionals, we have found the following to be useful lessons on best practices in engaging natural resources professionals and helping them increase their comfort with climate-informed planning.

\subsection{Give Participants a Tangible Outcome}

Asking professionals to bring their own project to a workshop directly addresses the desire for more hands-on, rather than passive, learning. This requirement lets participants understand explicitly how a process like the Adaptation Workbook might apply to their day-to-day work and lets them leave the workshop with a tangible list of adaptation actions. Training is more efficient because it allows professionals to get some of their own work done, making it worth their time. This is also why the bulk of the APP focuses on active group work, as opposed to lecture $[4,19]$. In addition, we often provide continuing education credits from accredited institutions (e.g., Society of American Foresters, International Society of Arboriculture) to assist with professional development requirements.

\subsection{Pre-Work (and Pre-Engagement) Are Important}

A major barrier in getting busy professionals to attend a training session is the time required. Initial meetings using the Adaptation Workbook were longer than two days; due to participant feedback, this was shortened to the 1.5-2 days described here. Requiring pre-work can capitalize on limited in-person time by offering background information and reading materials, especially for those with less exposure to climate information. It also serves to set expectations for the workshop structure and the active participation required and initiates focused thinking about climate-adaptive action. Finally, pre-work can minimize confusion by providing advice to ensure that participants choose an appropriate project for the workshop and clearly outline management goals and objectives. The online APP format is slightly different in that it allows for much of the pre-work content to be completed during the 7 weeks of sustained engagement with project teams.

\subsection{Keep It Small}

Participants routinely cite team conversation and cross-pollination with others in the cohort as the most valuable components of an APP. Generating quality interaction and the "social learning" that goes along with this [44] generally requires a limited number of participants. In our experience, project teams that include more than five or six people have trouble engaging all members in discussion. In addition, a total of five to ten projects within an APP can be optimal in allowing the project teams to share with one another, but without large-group activities becoming too long or redundant. Generally, a cohort of up to 30-35 people provides ample opportunity for group interaction. Online APPs can provide the flexibility to accommodate greater numbers of participants if they are divided among multiple discussion sessions, although the same size limitations in people per project team and teams within each discussion session still apply. Our online trainings have accommodated 60 people at a time, with participants joining for a presentation session followed by multiple discussion sessions of up to 30 people that engage in project team reporting, group activities, and discussion.

\subsection{Maintain a Regional, Sectoral, or Organizational Focus}

Holding APPs with a national audience or participants that are working in multiple different ecosystem types can be challenging. It becomes harder to present or assign 
targeted and useful information on climate impacts and vulnerabilities. Similarly, a team working on a boreal forest management project may not consider it particularly relevant to hear from a team working on a prairie restoration, reducing the potential for shared learning. Maintaining a regional or sectoral focus allows us to target specific climate impacts, group interests, or organizational contexts. This can also ensure that teams benefit from the full cohort interaction and discussion and hear about management scenarios relevant to their own. Having an organizational or agency commonality for an APP may also help provide a useful link between projects, allowing participants to approach the issue of climate change adaptation from a common organizational standpoint and pinpoint specific efficiencies or barriers.

\subsection{Recognize the Value of Partnerships and Trust}

We often host APPs with one or more partner organizations who serve as the primary trusted connection to potential participants. Many professionals are wary of committing valuable time, interacting with the controversial topic of climate change, or engaging with a prescriptive process that does not respect their values and goals. Our partner organizations serve as a trusted link between their communities and NIACS. Correspondingly, we rely on them to help determine the scope of the training, identify primary issues of interest (potentially requiring subject matter experts) and sensitize us to charged topics and terms. They may also help with logistical support, communication, and registration.

\subsection{Work with Existing Planning Processes, but Be Flexible to a Range of Contexts}

Organizations and agencies vary greatly in their missions, values, and decisionmaking processes. An advantage of the Adaptation Workbook process is that it can provide the flexibility to accommodate this organizational variety, along with needed structure. The structured stepwise process helps managers break down a complex topic into manageable steps, while affording flexibility that allows the process to be tailored to each organization's unique context. This flexibility also means that the process is not prescriptive or directly tailored to a single organization's planning and decision-making structure. Training like the APPs can be helpful in showing professionals how tools can fit in with their everyday planning and work activities and be adapted to fit the needs of specific groups or organizations. However, we believe it is critical to constantly solicit feedback on whether this is working as intended and to view negative feedback as an opportunity to better align our services with a context or community. For example, the creation of Dibaginjigaadeg Anishinaabe Ezhitwaad: A Tribal Climate Adaptation Menu [28] stemmed from feedback on the need for adaptation strategies that better reflected the values and perspectives of tribal and indigenous communities within the Great Lakes region.

\section{Concluding Remarks}

Information, tools and training on climate change adaptation in natural resources management have evolved considerably over the last decade. It is also clear that developing planning tools alone is not enough to ensure the implementation of climate-adaptive actions on the ground [14,15]. New frameworks are emerging but have not been tested extensively in real-world situations $[12,13]$. To further advance adaptation, effective climate services will need to help managers identify the planning tools that work best for them, and to use them to develop and implement climate adaptation actions. Our experience demonstrates how actively engaging managers with training that balances their needs and time constraints is one way to help move towards more intentional on-the-ground adaptation projects. We believe that lessons we have learned through our training approach can help accelerate the learning of adaptation professionals, tool developers, and researchers who are interested in applying adaptation tools in real-world management situations. At the same time, our lessons learned are based on APP participant feedback, our training experience, and interpretation of what has worked effectively at workshops. They are not drawn from a rigorous comparison of different training methods or a comprehensive 
scientific review of climate adaptation training approaches. We recognize the need for dedicated reviews and research on how to bridge the gap between adaptation planning tools for natural resources and on-the-ground action [19]. Both management and scientific communities are still in the early stages of climate adaptation and every example of intentional adaptation is both an advance and an opportunity for community learning. The approach used in the Adaptation Planning and Practices training can ground professionals with their own goals, help them identify adaptation actions appropriate for their resources and values and encourage them to share their learning while learning from others.

Supplementary Materials: The following are available online at https: / www.mdpi.com/article/ 10.3390/cli9050076/s1, Table S1: Table of APPs from 2013-2020, Table S2: Adaptation Workbook process and activities, Document S3: APP written evaluation form, Document S4: Forest Conservation and Stewardship Summit and Adaptation Workshop-participant agenda, Document S5: Forest Conservation and Stewardship Summit and Adaptation Workshop—facilitator agenda.

Author Contributions: Conceptualization, K.M.S., T.A.O., S.D.H., M.K.J., L.A.B., P.R.B.-L., P.D.S., C.L.P. and C.W.S.; Data curation, T.A.O.; Formal analysis, T.A.O.; Funding acquisition, C.W.S.; Methodology, K.M.S., T.A.O., S.D.H., M.K.J., L.A.B., P.R.B.-L., P.D.S., C.L.P. and C.W.S.; Project administration, M.K.J.; Supervision, C.W.S.; Writing-original draft, K.M.S., T.A.O. and S.D.H.; Writing-review \& editing, M.K.J., L.A.B., P.R.B.-L., P.D.S., C.L.P. and C.W.S. All authors have read and agreed to the published version of the manuscript.

Funding: We are grateful to American Forests, the USDA Forest Service Northern Research Station, and the USDA Climate Hubs for their support of this work.

Data Availability Statement: The data presented in this study may be available on request from the authors. The evaluation data are not publicly available due to privacy reasons.

Acknowledgments: The work we have described has evolved from the practical suggestions, patient testing, and genuine feedback of hundreds of participants-we thank them for their contributions to this process and service to natural resources conservation. We thank three anonymous reviewers for their helpful comments.

Conflicts of Interest: The authors declare no conflict of interest. The funders had no role in the design of the study; in the collection, analyses, or interpretation of data; in the writing of the manuscript, or in the decision to publish the results.

\section{References}

1. Janowiak, M.K.; Swanston, C.W.; Nagel, L.M.; Webster, C.R.; Palik, B.J.; Twery, M.J.; Bradford, J.B.; Parker, L.R.; Hille, A.T.; Johnson, S.M. Silvicultural Decisionmaking in an Uncertain Climate Future: A Workshop-Based Exploration of Considerations, Strategies, and Approaches; General Technical Report (GTR); U.S. Department of Agriculture, Forest Service, Northern Research Station: Newtown Square, PA, USA, 2011; pp. 1-14. [CrossRef]

2. Halofsky, J.E.; Peterson, D.L.; Joyce, L.A.; Millar, C.I.; Rice, J.M.; Swanston, C.W. Implementing climate change adaptation in forested regions of the United States. In Forest Conservation and Management in the Anthropocene: Adaptation of Science, Policy, and Practices, Proceedings; Sample, V.A., Bixler, R.P., Eds.; U.S. Department of Agriculture, Forest Service, Rocky Mountain Research Station: Fort Collins, CO, USA, 2014; pp. 229-243.

3. Anhalt-Depies, C.M.; Knoot, T.G.; Rissman, A.R.; Sharp, A.K.; Martin, K.J. Understanding Climate Adaptation on Public Lands in the Upper Midwest: Implications for Monitoring and Tracking Progress. J. Environ. Manag. 2016, 57, 987-997. [CrossRef] [PubMed]

4. Beier, P.; Hansen, L.J.; Helbrecht, L.; Behar, D. A How-to Guide for Coproduction of Actionable Science. Conserv. Lett. 2016, 10, 288-296. [CrossRef]

5. Cross, M.S.; Zavaleta, E.S.; Bachelet, D.; Brooks, M.L.; Enquist, C.A.F.; Fleishman, E.; Graumlich, L.J.; Groves, C.R.; Hannah, L.; Hansen, L.J.; et al. The Adaptation for Conservation Targets (ACT) Framework: A Tool for Incorporating Climate Change into Natural Resource Management. J. Environ. Manag. 2012, 50, 341-351. [CrossRef] [PubMed]

6. National Fish, Wildlife and Plants Climate Adaptation Partnership. National Fish, Wildlife and Plants Climate Adaptation Strategy; Association of Fish and Wildlife Agencies, Council on Environmental Quality, Great Lakes Indian Fish and Wildlife Commission, National Oceanic and Atmospheric Administration, U.S. Fish and Wildlife Service: Washington, DC, USA, 2012. [CrossRef]

7. Swanston, C.; Janowiak, M.; Butler, P.; Parker, L.; St. Pierre, M.; Brandt, L. Forest Adaptation Resources: Climate Change Tools and Approaches for Land Managers; Swanston, C., Janowiak, M., Eds.; U.S. Department of Agriculture, Forest Service, Northern Research Station: Newtown Square, PA, USA, 2012; pp. 1-121. [CrossRef] 
8. Stein, B.A.; Glick, P.; Edelson, N.; Staudt, A. (Eds.) Climate-Smart Conservation: Putting Adaptation Principles into Practice; National Wildlife Federation: Washington, DC, USA, 2014.

9. Beavers, R.L.; Babson, A.L.; Schupp, C.A. (Eds.) Coastal Adaptation Strategies Handbook; National Park Service: Washington, DC, USA, 2016.

10. Swanston, C.W.; Janowiak, M.K.; Brandt, L.A.; Butler, P.R.; Handler, S.D.; Shannon, P.D.; Derby Lewis, A.; Hall, K.; Fahey, R.T.; Scott, L.; et al. Forest Adaptation Resources: Climate Change Tools and Approaches for Land Managers, 2nd ed.; U.S. Department of Agriculture, Forest Service, Northern Research Station: Newtown Square, PA, USA, 2016; pp. 1-161. [CrossRef]

11. Stein, B.A.; Lawson, D.M.; Glick, P.; Wolf, C.M.; Enquist, C. Climate Adaptation for DoD Natural Resource Managers: A Guide to Incorporating Climate Considerations into Integrated Natural Resource Management Plans; National Wildlife Federation: Washington, DC, USA, 2019.

12. Schuurman, G.W.; Hawkins Hoffman, C.; Cole, D.N.; Lawrence, D.J.; Morton, J.M.; Magness, D.R.; Cravens, A.E.; Coving-ton, S.; O'Malley, R.; Fisichelli, N.A. Resist-Accept-Direct (RAD)—A Framework for the 21st-Century Natural Resource Manager; National Park Service: Fort Collins, CO, USA, 2020; pp. 1-20. [CrossRef]

13. Kershner, J.; Woodward, A.; Torregrosa, A. Integrating Climate Change Considerations into Natural Resource Planning-An Implementation Guide; U.S. Geological Survey: Corvallis, OR, USA, 2020; pp. 1-58. [CrossRef]

14. Moser, S.C.; Ekstrom, J.A. A framework to diagnose barriers to climate change adaptation. Proc. Natl. Acad. Sci. USA 2010, 107, 22026-22031. [CrossRef] [PubMed]

15. Woodruff, S.C.; Stults, M. Numerous strategies but limited implementation guidance in US local adaptation plans. Nat. Clim. Chang. 2016, 6, 796-802. [CrossRef]

16. Ontl, T.A.; Swanston, C.; Brandt, L.A.; Butler, P.R.; D'Amato, A.W.; Handler, S.D.; Janowiak, M.K.; Shannon, P.D. Adaptation pathways: Ecoregion and land ownership influences on climate adaptation decision-making in forest management. Clim. Chang. 2018, 146, 75-88. [CrossRef]

17. Kirchhoff, C.J.; Esselman, R.; Brown, D. Boundary organizations to boundary chains: Prospects for advancing climate science application. Clim. Risk Manag. 2015, 9, 20-29. [CrossRef]

18. Peterson St-Laurent, G.; Oakes, L.E.; Cross, M.; Hagerman, S. R-R-T (resistance-resilience-transformation) typology reveals differential conservation approaches across ecosystems and time. Commun. Biol. 2021, 4, 39. [CrossRef] [PubMed]

19. Stern, M.J.; Brousseau, J.; O'Brien, C.; Hurste, K.; Hansen, L. Climate Adaptation Workshop Delphi Study Report: Facilitators' Viewpoints on Effective Practices; Virginia Tech: Blacksburg, VA, USA; EcoAdap: Washington, DC, USA, 2020.

20. Janowiak, M.K.; Swanston, C.W.; Nagel, L.M.; Brandt, L.A.; Butler, P.R.; Handler, S.D.; Shannon, P.D.; Iverson, L.R.; Matthews, S.N.; Prasad, A.; et al. A practical approach for translating climate change adaptation principles into forest management actions. J. Forest. 2014, 112, 424-433. [CrossRef]

21. Fisichelli, N.; Schuurman, G.; Symstad, A.; Ray, A.; Friedman, J.; Miller, B.; Rowland, E. Resource Management and Operations in Central North Dakota: Climate Change Scenario Planning Workshop Summary November 12-13, 2015, Bismarck, ND; Natural Resource Report NPS/NRSS/NRR-2016/1262; National Park Service: Fort Collins, CO, USA, 2016; pp. 1-44. Available online: https: / /irma.nps.gov/DataStore/Reference/Profile/2230834 (accessed on 27 April 2021).

22. Climate Change Response Framework Home Page. Available online: https:/ / forestadaptation.org/ (accessed on 9 April 2021).

23. Brandt, L.A.; Butler, P.R.; Handler, S.D.; Janowiak, M.K.; Shannon, P.D.; Swanston, C.W. Integrating Science and Management to Assess Forest Ecosystem Vulnerability to Climate Change. J. Forest. 2017, 115, 212-221. [CrossRef]

24. Swanston, C.; Brandt, L.A.; Janowiak, M.K.; Handler, S.D.; Butler-Leopold, P.; Iverson, L.; Thompson, F.R., III; Ontl, T.A.; Shannon, P.D. Vulnerability of forests in the Midwest and Northeast United States to climate change. Clim. Chang. 2018, 146, 103-116. [CrossRef]

25. Adaptation Workbook Home Page. Available online: https://adaptationworkbook.org/ (accessed on 9 April 2021).

26. Janowiak, M.; Dostie, D.; Wilson, M.; Kucera, M.; Skinner, R.H.; Hatfield, J.; Hollinger, D.; Swanston, C. Adaptation Resources for Agriculture: Responding to Climate Variability and Change in the Midwest and Northeast; U.S. Department of Agriculture: Washington, DC, USA, 2016; pp. 1-70.

27. Shannon, P.D.; Swanston, C.W.; Janowiak, M.K.; Handler, S.D.; Schmitt, K.; Brandt, L.A.; Butler-Leopold, P.R.; Ontl, T. Adaptation strategies and approaches for forested watersheds. Clim. Serv. 2019, 13, 51-64. [CrossRef]

28. Tribal Adaptation Menu Team. Dibaginjigaadeg Anishinaabe Ezhitwaad: A Tribal Climate Adaptation Menu; Great Lakes Indian Fish and Wildlife Commission: Odanah, WI, USA, 2019; pp. 2-50.

29. Ontl, T.A.; Janowiak, M.K.; Swanston, C.W.; Daley, J.; Handler, S.; Cornett, M.; Hagenbuch, S.; Handrick, C.; Mccarthy, L.; Patch, N. Forest Management for Carbon Sequestration and Climate Adaptation. J. Forest. 2019, 118, 86-101. [CrossRef]

30. O’Toole, D.; Brandt, L.A.; Janowiak, M.K.; Schmitt, K.; Shannon, P.D.; Leopold, P.R.; Handler, S.D.; Ontl, T.A.; Swanston, C. Climate Change Adaptation Strategies and Approaches for Outdoor Recreation. Sustainability 2019, 11, 7030. [CrossRef]

31. Tingley, R.W., III; Paukert, C.; Sass, G.G.; Jacobson, P.C.; Hansen, G.J.A.; Lynch, A.J.; Shannon, P.D. Adapting to climate change: Guidance for the management of inland glacial lake fisheries. Lake Reserv. Manag. 2019, 35, 435-452. [CrossRef]

32. Staffen, A.; O'Connor, R.; Johnson, S.E.; Shannon, P.D.; Kearns, K.; Zine, M.; Sheehan, M.; Fleener, J.; Panci, H.; Volkening, A. Climate Adaptation Strategies and Approaches for Conservation and Management of Non-Forested Wetlands; USDA Northern Forests Climate Hub: Houghton, MI, USA, 2019; pp. 1-51. 
33. Swanston, C.W.; Brandt, L.A.; Butler-Leopold, P.R.; Hall, K.R.; Handler, S.D.; Janowiak, M.K.; Merriam, K.; Meyer, M.; Molinari, N.; Schmitt, K.M.; et al. Adaptation Strategies and Approaches for California Forest Ecosystems; Technical Report CACH-2020-1; USDA California Climate Hub: Davis, CA, USA, 2020; pp. 1-63.

34. Halofsky, J.E.; Peterson, D.L. Climate change vulnerabilities and adaptation options for forest vegetation management in the northwestern USA. Atmosphere 2016, 7, 46. [CrossRef]

35. Reidmiller, D.R.; Avery, C.W.; Easterling, E.R.; Kunkel, K.E.; Lewis, K.L.M.; Maycock, T.K.; Stewart, B.C. (Eds.) Impacts, Risks, and Adaptation in the United States: Fourth National Climate Assessment; U.S. Global Change Research Program: Washington, DC, USA, 2018; Volume 2, p. 1515. [CrossRef]

36. Wisconsin Initiative on Climate Change Impacts, Plants and Natural Communities Working Group. Climate Change Vulnerability Assessments (CCVAs). Available online: https:/ / wicci.wisc.edu/plants-and-natural-communities-working-group/climatechange-vulnerability-assessments-ccvas / (accessed on 9 April 2021).

37. Janowiak, M.; Mahaffey, A.; Riely, C. Moving the Needle: A Review of Needs to Increase Climate Adaptation in the Forests of New England; Forest Stewards Guild: Santa Fe, NM, USA, 2020; pp. 1-31.

38. Hall, J.A.; Fleishman, E. Demonstration as a Means to Translate Conservation Science into Practice. Conserv. Biol. 2010, 24, 120-127. [CrossRef]

39. Climate Change Response Framework. Leelanau Conservancy: Palmer Woods Forest Reserve. Available online: https:// forestadaptation.org/palmer_woods (accessed on 27 April 2021).

40. Climate Change Response Framework. Bay Mills Indian Community: Sugar Island. Available online: https:/ / forestadaptation. org/sugar_island (accessed on 27 April 2021).

41. Climate Change Response Framework. Little Traverse Conservancy: Jack and Tucker Harris Working Forest Reserve. Available online: https: / forestadaptation.org/harris_reserve (accessed on 27 April 2021).

42. Climate Change Response Framework. Pokagon Band of Potawatomi: Dowagiac Tree Translocation. Available online: https: / / forestadaptation.org/pokagon_dowagiac (accessed on 27 April 2021).

43. Climate Change Response Framework. Little Traverse Bay Bands of Odawa Indians: Ziibimijwang Farm. Available online: https:/ / forestadaptation.org/ziib_farm (accessed on 27 April 2021).

44. Rumore, D.; Schenk, T.; Susskind, L. Role-Play Simulations for Climate Change Adaptation Education and Engagement. Utah Law Fac. Scholarsh. 2016, 30. Available online: http:/ / dc.law.utah.edu/scholarship/30 (accessed on 5 May 2021). [CrossRef] 